\title{
Functional Role of the Cerebellum in Gamma-Band Synchronization of the Sensory and Motor Cortices
}

\author{
Daniela Popa, ${ }^{1,2,3}$ Maria Spolidoro, ${ }^{1,2,3 *}$ Rémi D. Proville, ${ }^{1,2,3 *}$ Nicolas Guyon, ${ }^{1,2,3}$ Lucile Belliveau, ${ }^{1,2,3}$ \\ and Clément Léna ${ }^{1,2,3}$ \\ ${ }^{1}$ Ecole Normale Supérieure, Institut de Biologie de l'ENS, IBENS, ${ }^{2}$ INSERM, U1024, and ${ }^{3}$ CNRS, UMR 8197, F-75005 Paris, France
}

\begin{abstract}
The cerebellum is an essential structure for the control of movement. It sends abundant ascending projections to the cerebral cortex via the thalamus, but its contribution to cortical activity remains largely unknown. Here we studied its influence on cortical neuronal activity in freely moving rats. We demonstrate an excitatory action of the cerebellum on the motor thalamus and the motor cortex. We also show that cerebellar inactivation disrupts the gamma-band coherence of local field potential between the sensory and motor cortices during whisking. In contrast, phase locking of neuronal activities to local gamma oscillations was preserved in the sensory and motor cortices by cerebellar inactivation. These results indicate that the cerebellum contributes to coordinated sensorimotor cortical activities during motor activation and thus participates in the multiregional cortical processing of information.
\end{abstract}

\section{Introduction}

The cerebellum is a structure involved in motor control, and its basic circuit and algorithm are used in a wide variety of functions (Dean et al., 2010). Many studies have been focused on the cerebellar contribution to reflexes [e.g., eye-blink conditioning (Thompson, 2005), ocular reflexes (Boyden et al., 2004; Lisberger, 2009)], to vestibular function (Angelaki and Cullen, 2008), and to the modulation of descending motor commands [e.g., eye saccade adaptation (Robinson and Fuchs, 2001)]. However, in addition to its direct role in motor tuning, the cerebellum has been proposed to be involved in brain computations (Ito, 2008) such as sensorimotor processing in sensory discrimination (Gao et al., 1996) and prediction of sensory consequences of motor actions (Blakemore et al., 1998; Tseng et al., 2007). Strong anatomical evidence indicates that the cerebellum has reciprocal interactions with the thalamocortical system (Kelly and Strick, 2003), with a descending pathway from the cortex to the cerebellum via the pontine nucleus (Leergaard and Bjaalie, 2007) and an ascending pathway via the thalamus (Aumann et al., 1994; Teune et al., 2000). The importance of this system is exemplified by the remarkable conservation by evolution in mammals of the proportion of neurons in the cerebral cortex and cerebellum (Herculano-Houzel, 2010). Synchronized neurophysiological

Received Nov. 30, 2012; revised March 1, 2013; accepted March 5, 2013.

Author contributions: D.P. and C.L. designed research; D.P., M.S., R.D.P., N.G., L.B., and C.L. performed research; D.P., M.S., R.D.P., N.G., L.B., and C.L. analyzed data; D.P. and C.L. wrote the paper.

This work was supported by Agence Nationale de Recherche to C.L. (CeCoMoD ANR-09-MNPS-38, Sensocode ANR-11-BSV4-028) and to D.P. (CereDySTim ANR-12-JSV4-0004) and by the Institut National de la Santé et de la Recherche Médicale to C.L. and D.P. M.S. was supported by a postdoctoral Fellowship from Marie-Curie (CBTOUCHFP7-People-2011-IEF) and R.D.P. by Fondation pour la Recherche Medicale.

${ }^{*}$ M.S. and R.D.P. contributed equally to this work.

Correspondence should be addressed to either Daniela Popa or Clément Léna, Cerebellum Team, Institut de

Biologie de I'ENS, U1024 UMR 8197, École Normale Supérieure, 46 rue d'Ulm, F-75005 Paris, France, E-mail: daniela.popa@ens.fr or clement.lena@ens.fr.

DOI:10.1523/JNEUROSCI.5521-12.2013

Copyright $\odot 2013$ the authors $\quad 0270-6474 / 13 / 336552-05 \$ 15.00 / 0$ oscillations during anesthesia (Rowland et al., 2010) and motor tasks (O'Connor et al., 2002; Courtemanche and Lamarre, 2005; Soteropoulos and Baker, 2006; Ros et al., 2009) have been reported multiple times in cerebrocerebellar loops. While these oscillations are hints of functional interactions between the structures, they provide little indication on the contribution of the cerebellum to the activity of the cerebral cortex. In the rodents, the cerebellum is a hub of afferent inputs from the whisker's sensorimotor system, a tactile system formed by the mobile face vibrissae (Bosman et al., 2011). This system is used by rodents to explore and collect tactile information, such as object features, size, and shape (Diamond et al., 2008), in their surrounding environment. The information is acquired actively during whisking, a rhythmic and collective forward and backward motion of the whiskers, adjusted in relation to the topology of the environment (Diamond et al., 2008). The disruption of the fiber tract carrying the cortical efferent information to the cerebellum prevents the animals from using the tactile information from the whiskers (Jenkinson and Glickstein, 2000), indicating the functional importance of cerebrocerebellar interactions. To analyze the contribution of the cerebellum to whiskers' sensorimotor processing, we recorded unit activity and local field potential (LFP) simultaneously in the motor thalamus (VAL), primary motor (M1), and sensory (S1) cortices of the vibrissae at rest and while the rats are whisking during free exploration, and we examined the impact of cerebellar inactivation on these activities.

\section{Materials and Methods}

Procedures were conducted in accordance with institutional guidelines and in compliance with national and European laws and policies. Adult male Sprague Dawley rats (3-5 months old; 300-500 g; Charles River Laboratories) were housed individually with ad libitum access to food and water and maintained on a $12 \mathrm{~h}$ light/dark cycle.

Surgery. Rats were anesthetized with a mixture of isoflurane and $\mathrm{O}_{2}$, and administered atropine methyl nitrate to aid breathing, and maintained at physiological core temperature. After a local anesthetic injec- 

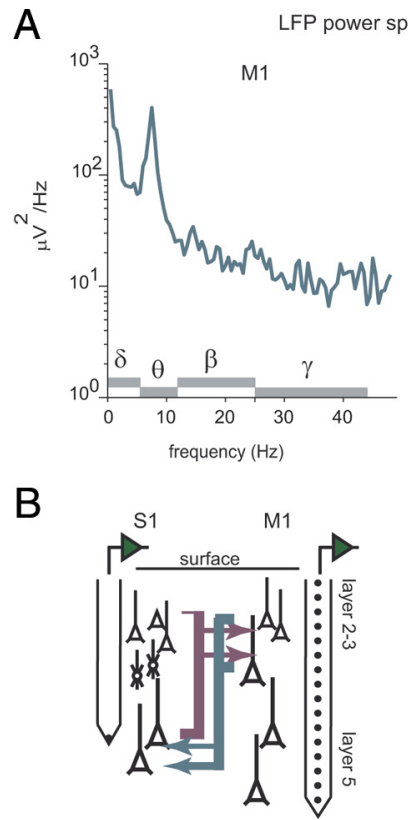
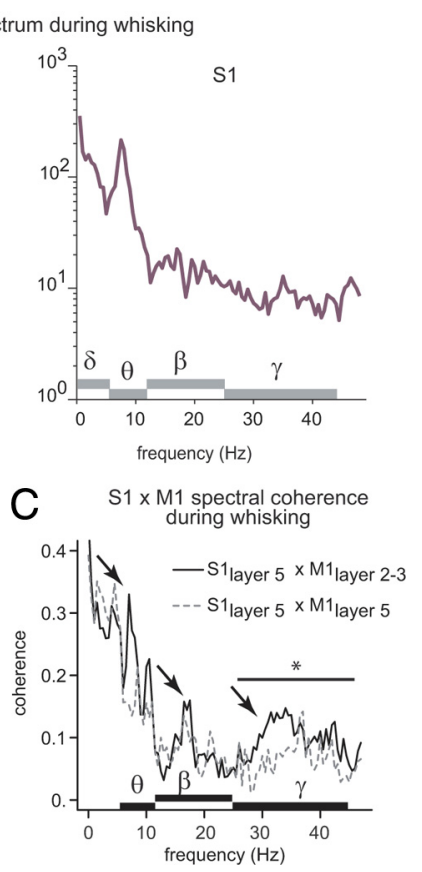

Figure 1. The LFP power and coherence spectra during free whisking. $A$, Example of power spectrum in the delta $(1-6 \mathrm{~Hz})$, theta $(6-12 \mathrm{~Hz})$, beta $(12-25 \mathrm{~Hz})$, and gamma $(25-45 \mathrm{~Hz})$ bands recorded in the motor (M1) and sensory (S1) cortices of vibrissae. $\boldsymbol{B}$, Scheme of anatomical connectivity (from Mao et al., 2011) and of the electrode position in S1 (layer 5) and in M1 (layers 1-5) of vibrissae. C, Average coherence spectra between the deep S1 LFP and the deep (dashed line) and superficial (plain line) M1 LFP ( $n=7$ rats). The coherence spectrum in the gamma band depends on the depth in the motor cortex. The average coherence in the gamma band is significantly higher between the deep $\mathrm{S1}$ and the superficial M1 LFP $\left({ }^{*} p<0.05\right)$.

tion (lidocaine, s.c.), the scalp was incised, and small burr holes were made in the skull above the cerebellum for the insertion of a guide cannula into the interpositus cerebellar nuclei (from the bregma in millimeters: anteroposterior (AP) -10.85 , mediolateral (ML) 3, dorsoventral (DV) 5.8), and above the contralateral VAL, M1, and S1 of vibrissae where linear electrodes or bundles of eight microwires were inserted in each of these structures under stereotaxic guidance (from the bregma in millimeters: VAL: AP - 2.45, ML 2.4, DV 6; M1: AP + 2, ML 1; and S1: AP $-2, \mathrm{ML} 6)$. The electrodes were fixed with dental cement. The rats were allowed a minimum of $3 \mathrm{~d}$ to recover from the surgery.

Cerebellar pharmacological inactivation. Muscimol ( $4 \mu \mathrm{mol}$ in $1 \mu \mathrm{l}$ of saline) was administrated via the cerebellar guide cannula in awake, freely moving animals, during exploration. For this purpose, a hollow silica fiber (150 $\mu \mathrm{m}$ outer diameter) connected to a Hamilton syringe containing muscimol was inserted in a guide cannula (29G). At the end of the injection, the silica fiber was removed from the cannula and was stocked until the next session. At the end of behavioral experiments, a dose of muscimol coupled with a fluorescent molecule was injected to evaluate the area affected by the muscimol injections. The animals were given an overdose of pentobarbital $\left(100 \mathrm{mg} \mathrm{kg}^{-1}\right.$, i.p.) and perfused intracardially with $0.9 \%$ saline, followed by paraformaldehyde (PFA; $4 \%)$. The brains were then removed, stored in PFA $(4 \%)$, sectioned at a thickness of $90 \mu \mathrm{m}$. We only included data from recording sites histologically confirmed to be in the structures of interest. The controls with muscimol coupled with a fluorescent molecule revealed that, with the parameters used here, muscimol remained confined to the cerebellar nuclei, diffusing $\leq 1 \mathrm{~mm}^{3}$ from the center of the infusion site.

In vivo recordings. Before and after muscimol administration, spontaneous unit and LFP activity were recorded with a sampling rate of $25 \mathrm{kHz}$ (Tucker-Davis Technologies System 3) while the animal freely explored the recording arena. Three to five salient objects were present in the arena to maintain the animal's interest for the environment. The animal was filmed with a monochrome video camera $(50 \mathrm{~Hz}$, AVT Marlin F033). The whisking periods were scored off-line.

Neurophysiological data analysis. Linear electrodes with 16 channels (NeuroNexus) were used to study the lamination of LFP power and coherence across cortical layers (de Solages et al., 2008). Bundle electrodes were used for recordings in the motor thalamus, motor cortex, and sensory cortex (Popa et al., 2010). Data were analyzed off-line with custom software written in MATLAB 7 (MathWorks) and R (http://www.R-project.org).

\section{$\leftarrow$}

Figure 2. Cerebellar inactivation does not change the LFP power spectrum or whisking parameters. $\boldsymbol{A}$, Scheme of the experiment. The muscimol infusion disrupts neither $(\boldsymbol{B})$ the LFP power spectrum in $\mathrm{M} 1$ and $\mathrm{S} 1$ in the delta $(1-6 \mathrm{~Hz})$, theta $(6-12 \mathrm{~Hz})$, beta $(12-25 \mathrm{~Hz})$, and gamma $(25-45 \mathrm{~Hz})$ bands during whisking, nor the duration of whisking bouts $(C)$ in freely behaving animals ( $n=12$ rats). C, Top, Example distribution of the duration of the whisking episodes (density estimated with a Gaussian kernel with a width of $0.5 \mathrm{~s}$ ). Bottom, Mean episode duration for all animals. D, Impact of cerebellar inactivation on whisking behavior in head-fixed animals. (a) Video still of the mouse head and whiskers. (b) Angular deflection of a single whisker during a whisking episode. (c) Power spectra density (PSD) of the episode in $(\boldsymbol{b})$; the arrow indicates the peak whisking frequency. $(\boldsymbol{d}-\boldsymbol{f})$ Example distribution of the cycle amplitudes, duration, and frequency of whisking episodes from a single animal (densities estimated with Gaussian kernels with a width of $1^{\circ}, 5 \mathrm{~ms}, 0.2 \mathrm{~Hz}$, respectively). There is a significant shift toward higher frequencies after the cerebellar inactivation. ctrl., control; mus., muscimol. ${ }^{*} p<0.05$ (paired $t$ test), significantly different from control condition. 
Power spectral density estimates were obtained with the Welch method with $2 \mathrm{~s}$ windows overlapping $1 \mathrm{~s}$ from the signal downsampled to 1 $\mathrm{kHz}$. Comparison of the spectral power per band between control and muscimol conditions was performed on the normalized change in power $\left(\mathrm{PW}_{\text {muscimol }}-\mathrm{PW}_{\text {control }}\right) /\left(\mathrm{PW}_{\text {muscimol }}+\right.$ $\left.\mathrm{PW}_{\text {control }}\right)$. Coherence estimates were obtained from cross-power spectra density estimates of pairs of LFP recordings, using the same parameters. Spike sorting was performed on digitally filtered data (high-pass Butterworth filter $>300 \mathrm{~Hz}$ ), using a supervised $k$-means clustering algorithm. To examine the relationship between gamma oscillations and unit activity we constructed perievent histograms of unit activity around the positive peaks of gamma oscillations recorded in the same structure. We first isolated gamma $(25-40 \mathrm{~Hz})$ by filtering the LFP and identifying episodes with strong gamma, i.e., gamma cycles with positive peaks exceeding the average plus 2 SD of the filtered signal. For each cell with $>50$ spikes during these high gamma episodes, the uniformity of the phase distribution was then tested with a Rayleigh test. The phase distributions were fitted with a von Mises distribution to determine the preferred phase. The concentration parameter $\kappa$ of the von Mises fits was in the range 0.02-2.2 for 151 cells; 3 cells recorded in the motor cortex after muscimol had an extremely strong phase locking $(\kappa>3)$, and were taken out as outliers.

Behavior analysis. The effect of muscimol on whisker movements was examined in a separate set of head-fixed rats $(n=3)$ with all whiskers, except 3-4 from the C-row, were bilaterally trimmed. A small metal plate was implanted on the skull with two screws to keep the head fixed. After $3 \mathrm{~d}$ of recovery, the animals were habituated to the head-restrained setup for an increasing amount of time (from 20 s to 60 min reached in $2-3 \mathrm{~d}$ ). Whiskers were filmed using a high-speed camera operating at $300 \mathrm{~Hz}$ and a $1 \mathrm{~ms}$ exposure time. Cumulated film duration per condition and per animal ranged from 8-15 min in which 3800-16,200 whisking cycles were measured.

Whisker tracking was performed off-line using the OpenCV library. The whiskers were entirely automatically detected on the Laplacian-transformed frames by the OpenCV built-in contour detection algorithm, and matched from frame to frame. The angle between the base of the whisker and the animal mediolateral axis was computed for each whisker in each frame. Amplitude and period of whisking were derived from the identification of local extrema; cycles of $<0.2$ radians of amplitude were filtered out to avoid the detection of small twitching.

All values are reported as average \pm SEM. Statistical analyses consisted of ANOVAs followed by $t$ tests, unless otherwise specified.

\section{Results}

We first searched for the physiological signature of coordinated activities in the sensory and motor cortices of the whisker system by studying the power and the coherence spectra of the LFPs in these structures during whisking. The LFPs exhibited prominent synchronized oscillations in the theta band, as evidenced by peaks in the power (Fig. 1A) and coherence spectra (Figs. 1C, 3A). Peaks in the gamma band of coherence spectra were also observed during whisking (Figs. $1 C, 3 A$ ). The coherent activities in the theta, beta, and gamma band were best recorded between the

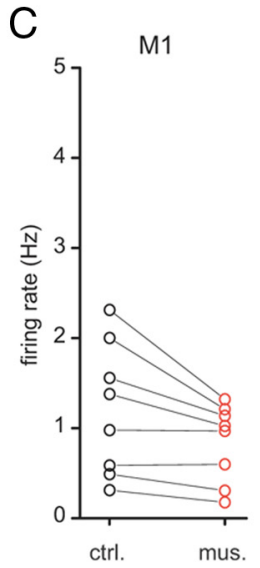

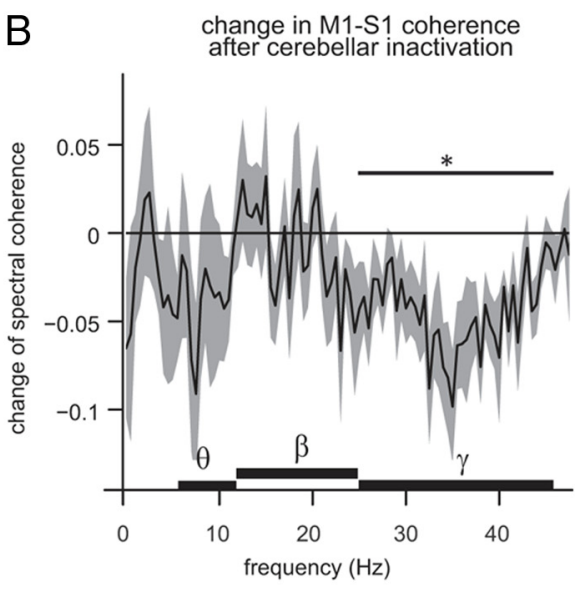

hanges of firing rate during whisking after cerebellar inactivation
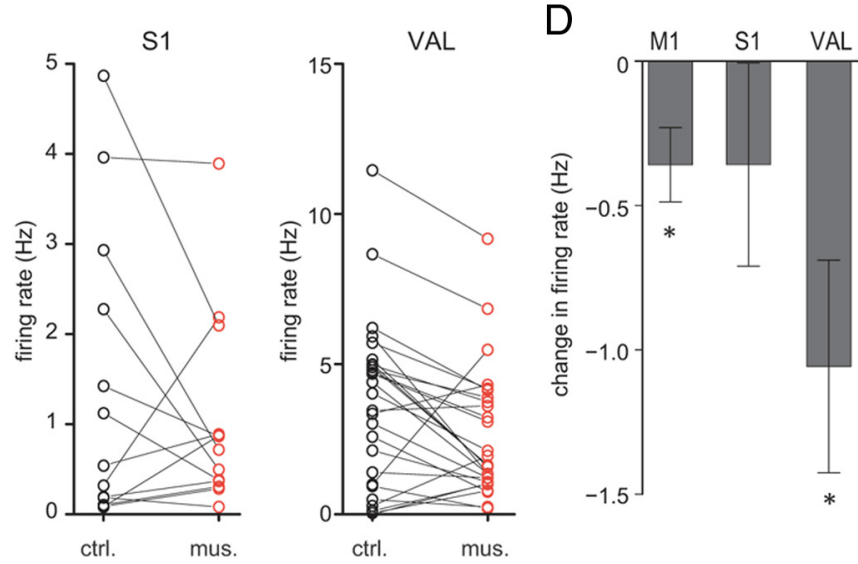

Figure 3. Cerebellar inactivation disrupts gamma-band synchrony between the primary sensory and motor cortices and decreases the firing rate in the motor cortex and motor thalamus during free whisking. The peak in the average gamma-band coherence spectra $(\boldsymbol{A})$ is absent after intracerebellar muscimol infusion, and the average coherence is significantly reduced only in mus (VAL) before (ctrl.) and after (mus.) cerebellarinactivation; the average duration of whisking used to compute

deep layers of the sensory cortex (layer 5) and the upper layers of the motor cortex (Fig. 1C); this pattern indeed corresponds to the main reciprocal anatomical connections between the sensory and motor cortices (Fig. 1B) (Mao et al., 2011). We then restricted our following recordings to these layers.

The whisking movements are thought to be generated by midbrain pattern generators but higher motor areas also regulate the movements (Bosman et al., 2011). We therefore examined the impact on whisking behavior of transient cerebellar inactivation with injections of the GABAergic agonist muscimol in the cerebellar nuclei (Fig. 2A). The cerebellar inactivation did not suppress the whisking behavior, as observed after lesion of the cerebrocerebellar tract (Jenkinson and Glickstein, 2000), nor change the duration of whisking episodes (Fig. $2 C ; p=0.59$ ). However, the fraction of the total whisking time spent bringing the whiskers in contact with objects was significantly enhanced after cerebellar inactivation (fraction of time spent whisking against objects control: $8.7 \% \pm 3.4$, muscimol: $17.0 \% \pm 4.3, p=$ $0.026)$. To test for fine changes in whisking, we performed a series of experiments in awake head-fixed animals with fast video tracking of the whisker movements. We found that neither the amplitude (control: $27.9 \pm 0.3^{\circ}$ muscimol $26.9 \pm 1.2^{\circ}, p=0.49$ ) nor 
the period (control: $121 \pm 7 \mathrm{~ms}$, muscimol $130 \pm 7 \mathrm{~ms}, p=0.36$ ) of whisking movements were altered by cerebellar inactivation (Fig. 2D). However, in each animal, the average whisking frequency, measured as the peak in the power spectrum of whiskers' angle time series (Fig. 2D), was significantly shifted toward higher frequencies after cerebellar inactivation (control: $6.17 \pm 0.07 \mathrm{~Hz}$, effect of muscimol: shift of $+0.37 \pm 0.21 \mathrm{~Hz}$ ). These results indicate that whisking is only mildly affected by cerebellar inactivation, but that the rat increases the time spent exploring objects when the cerebellum is removed from the network.

We next examined the contribution of the cerebellum to LFP activities in the motor and sensory cortices. Interestingly, the cerebellar inactivation selectively decreased the coherence of sensory and motor cortices LFPs in a frequency-dependent manner (interaction term for treatment:frequency $F_{(1,2145)}=6.37, p=$ 0.0117). We found that this effect is significant in the gamma band (Fig. $3 A, B ; p=0.02$ ), while no change was found in the cortical LFP power (Fig. $2 B$; delta $p=0.28$, theta $p=0.84$, beta $p=0.29$, gamma $p=0.40)$. We verified that the gamma-band coherence was restored overnight to baseline values $(p=0.48)$. We also verified that such change in gamma-band coherence was not seen during periods of grooming, during which whiskers were brushed but not moved (change in gamma-band coherence after muscimol injection: $-15 \pm 21 \%$ of control value, $p=0.49$ ). During motor activation, the cerebellum thus plays a determinant role in establishing sensorimotor cortical gamma-band coherence.

During free whisking, neurons recorded in the motor thalamus, motor cortex, and sensory cortex globally increased their average firing rate compared with their average baseline firing rate (VAL: $+81 \pm 12 \%, n=65$, pairwise $p<0.001 ; \mathrm{M} 1:+29 \pm$ $12 \%, n=50$, pairwise $p=0.02 ; \mathrm{S} 1:+32 \pm 20 \%, n=37$, pairwise $p<0.001)$. We then examined the influence of the cerebellum on the firing rate of the thalamocortical pathway (Fig. $3 C, D$ ). The inactivation of the cerebellum produced an overall decrease in the firing rate of cells recorded in the motor thalamus and in the motor cortex, but not in the sensory cortex during the episodes of free whisking (VAL: $n=29$, pairwise $p=0.006$; M1: $n=9$, pairwise $p=0.034 ; \mathrm{S} 1: n=15$, pairwise $p=0.2$; Fig. $3 C, D)$. These results indicate that the net effect of the cerebellum during motor activation is excitatory, and is consistent with the action of the cerebellum on the motor thalamus and cortical neurons found in anesthetized condition (Sawyer et al., 1994; Na et al., 1997).

The reduced cortical excitation after cerebellar inactivation might reduce local gamma generation processes (Cardin et al., 2009) and consequently gamma phase locking of cells in the cortex (Fries et al., 2007). To address this issue, we asked whether deficits in gamma cortical coherence after cerebellar inactivation go along with a reduction in phase locking with local gamma in the motor and sensory cortices (Fig. $4 A)$. We found that a similar proportion $\left(\sim 50 \%, \chi^{2}\right.$ M1-VAL: $p=0.39 ;$ M1-S1: $p=0.42$; VAL-S1: $p=1.00$; Fig. $4 B)$ of neurons displayed significant phase locking to their local gamma rhythm before and after inactivation, and that the strength of phase locking was unaffected by the cerebellar inactivation for $\mathrm{M} 1$ and $\mathrm{S} 1$, while it was reduced in VAL $(\mathrm{M} 1: p=0.1 ; \mathrm{S} 1: p=$ 0.21 ; VAL: $p<0.001$; Fig. $4 C$ ). Thus, the local gamma modulation of cortical firing does not require the cerebellum, and only long-range coordination of the neuronal activity in gamma band is disrupted after the cerebellar inactivation.

\section{Discussion}

The present study was undertaken to shed light on the neurophysiological basis of the cerebellar contribution to the sensorimotor integration in the whisker system. Our results
A example of units phase-locked to local gamma
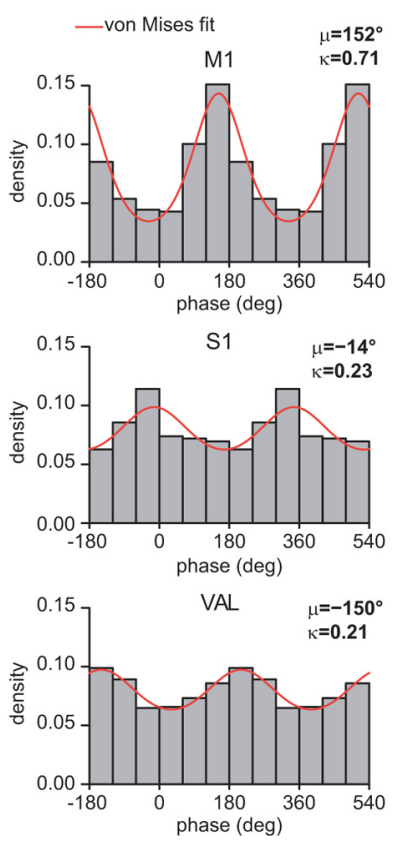

B

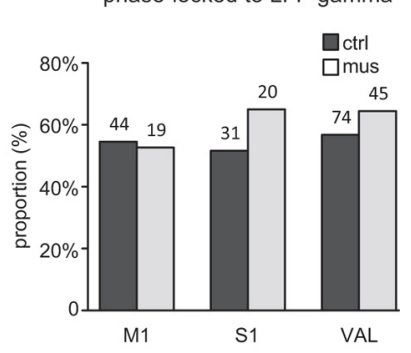
locking to local gamma

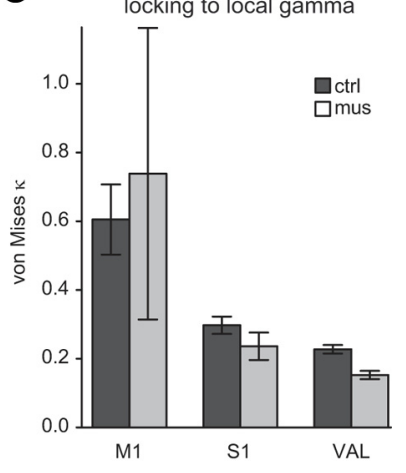

C intensity of phase-

Figure 4. Phase locking of cell firing to local gamma is unchanged by cerebellar inactivation. A, Gamma phase distribution for example units in the whisker motor (M1) and sensory (S1) cortices and motor thalamus (VAL); the von Mises fit is plotted with the red line and the parameters ( $\mu$ and $\kappa$ ) indicated. The proportions $(\boldsymbol{B})$ and strength of phase locking $(\boldsymbol{C})$ of cells significantly phase locked to local gamma is unchanged by cerebellar inactivation.

demonstrate that the cerebellum exerts a powerful excitatory influence on the cortical activity and is required for the gamma coherence between the sensory and the motor cortices during tactile exploration.

Gamma-band activity may be generated at multiple levels in the brain, including within the cortex, the thalamus, and also the cerebellum (De Zeeuw et al., 2008; Middleton et al., 2008). Cortical gamma LFP is generated by local neuronal elements (Katzner et al., 2009), and multiple processes may contribute to its generation (Buzsáki et al., 2012); the observed synchronization in the gamma band indicates that some of these processes are coordinated in the motor and sensory cortices during whisking. Cortical gamma is under the control of specific interneuronal populations (Cardin et al., 2009) but the mechanisms underlying its synchronization across regions are still unresolved. The thalamus has been proposed to play a strong role in synchronizing the gamma oscillations across cortical areas (Steriade et al., 1996). The cerebellum sends heavy projections (Aumann et al., 1994; Teune et al., 2000) to the motor thalamus (VAL), but also projects to the (high-order) posterior thalamic nucleus, which is reciprocally connected to the primary motor and sensory cortices, and to the intralaminar nuclei, which may be more specifically engaged in the coordination of activity across cortical areas (Jones, 2001). The cerebellum may thus exert its effect on coherent gamma-band activities in the primary sensory and motor cortices via the cerebellothalamic pathway. Since these cortices in the whisker system play complementary roles in motor control (Matyas et al., 2010) and in perception of location (Kleinfeld and Deschenes, 2011), this synchronization could contribute both to motor and cognitive aspects of the active sensory system. Parts of the cerebellar cortex process the whisker sensory information (Bosman et al., 2010) but the functional importance of this activity is 
still unknown. Interestingly, while the cerebellar inactivation seemed to minimally perturb whiskers' movements, a longer fraction of the total whisking time was spent exploring objects, suggesting a failure to adapt to familiar objects (Anderson et al., 2012).

Gamma-band coherent activities between cells and brain regions has been repeatedly observed in information processing, attention, and memory (Jensen et al., 2007). In light of the extended cortical areas receiving inputs from the cerebellum (Strick et al., 2009; Sultan et al., 2012), the cerebellar control of cortical gamma coherence could contribute to these functions. Moreover, abnormalities in functional connectivity between brain areas are important for the pathophysiological mechanisms underlying neuronal disorders (Herrmann and Demiralp, 2005; Verret et al., 2012). Our findings suggest that attention and memory deficits observed in cerebellar dysfunctions, such as in essential tremor (Passamonti et al., 2011), might result from impaired sensorimotor cortical processing consecutive to cerebellar neurodegeneration.

\section{References}

Anderson SR, Porrill J, Pearson MJ, Pipe AG, Prescott TJ, Dean P (2012) An internal model architecture for novelty detection: implications for cerebellar and collicular roles in sensory processing. PLoS One 7:e44560. CrossRef Medline

Angelaki DE, Cullen KE (2008) Vestibular system: the many facets of a multimodal sense. Annu Rev Neurosci 31:125-150. CrossRef Medline

Aumann TD, Rawson JA, Finkelstein DI, Horne MK (1994) Projections from the lateral and interposed cerebellar nuclei to the thalamus of the rat: a light and electron microscopic study using single and double anterograde labelling. J Comp Neurol 349:165-181. CrossRef Medline

Blakemore SJ, Wolpert DM, Frith CD (1998) Central cancellation of selfproduced tickle sensation. Nat Neurosci 1:635-640. CrossRef Medline

Bosman LW, Koekkoek SK, Shapiro J, Rijken BF, Zandstra F, van der Ende B, Owens CB, Potters JW, de Gruijl JR, Ruigrok TJ, De Zeeuw CI (2010) Encoding of whisker input by cerebellar Purkinje cells. J Physiol 588: 3757-3783. CrossRef Medline

Bosman LW, Houweling AR, Owens CB, Tanke N, Shevchouk OT, Rahmati N, Teunissen WH, Ju C, Gong W, Koekkoek SK, De Zeeuw CI (2011) Anatomical pathways involved in generating and sensing rhythmic whisker movements. Front Integr Neurosci 5:53. Medline

Boyden ES, Katoh A, Raymond JL (2004) Cerebellum-dependent learning: the role of multiple plasticity mechanisms. Annu Rev Neurosci 27:581-609. CrossRef Medline

Buzsáki G, Anastassiou CA, Koch C (2012) The origin of extracellular fields and currents-EEG, ECoG, LFP and spikes. Nat Rev Neurosci 13:407-420. CrossRef Medline

Cardin JA, Carlén M, Meletis K, Knoblich U, Zhang F, Deisseroth K, Tsai LH, Moore CI (2009) Driving fast-spiking cells induces gamma rhythm and controls sensory responses. Nature 459:663-667. CrossRef Medline

Courtemanche R, Lamarre Y (2005) Local field potential oscillations in primate cerebellar cortex: synchronization with cerebral cortex during active and passive expectancy. J Neurophysiol 93:2039-2052. Medline

Dean P, Porrill J, Ekerot CF, Jörntell H (2010) The cerebellar microcircuit as an adaptive filter: experimental and computational evidence. Nat Rev Neurosci 11:30-43. CrossRef Medline

de Solages C, Szapiro G, Brunel N, Hakim V, Isope P, Buisseret P, Rousseau C, Barbour B, Léna C (2008) High-frequency organization and synchrony of activity in the purkinje cell layer of the cerebellum. Neuron 58:775-788. CrossRef Medline

De Zeeuw CI, Hoebeek FE, Schonewille M (2008) Causes and consequences of oscillations in the cerebellar cortex. Neuron 58:655-658. CrossRef Medline

Diamond ME, von Heimendahl M, Knutsen PM, Kleinfeld D, Ahissar E (2008) 'Where' and 'what' in the whisker sensorimotor system. Nat Rev Neurosci 9:601-612. CrossRef Medline

Fries P, Nikolić D, Singer W (2007) The gamma cycle. Trends Neurosci 30:309-316. CrossRef Medline

Gao JH, Parsons LM, Bower JM, Xiong J, Li J, Fox PT (1996) Cerebellum implicated in sensory acquisition and discrimination rather than motor control. Science 272:545-547. CrossRef Medline
Herculano-Houzel S (2010) Coordinated scaling of cortical and cerebellar numbers of neurons. Front Neuroanat 4:12. Medline

Herrmann CS, Demiralp T (2005) Human EEG gamma oscillations in neuropsychiatric disorders. Clin Neurophysiol 116:2719-2733. CrossRef Medline

Ito M (2008) Control of mental activities by internal models in the cerebellum. Nat Rev Neurosci 9:304-313. CrossRef Medline

Jenkinson EW, Glickstein M (2000) Whiskers, barrels, and cortical efferent pathways in gap crossing by rats. J Neurophysiol 84:1781-1789. Medline Jensen O, Kaiser J, Lachaux JP (2007) Human gamma-frequency oscillations associated with attention and memory. Trends Neurosci 30:317-324. CrossRef Medline

Jones EG (2001) The thalamic matrix and thalamocortical synchrony. Trends Neurosci 24:595-601. CrossRef Medline

Katzner S, Nauhaus I, Benucci A, Bonin V, Ringach DL, Carandini M (2009) Local origin of field potentials in visual cortex. Neuron 61:35-41. CrossRef Medline

Kelly RM, Strick PL (2003) Cerebellar loops with motor cortex and prefrontal cortex of a nonhuman primate. J Neurosci 23:8432-8444. Medline

Kleinfeld D, Deschênes M (2011) Neuronal basis for object location in the vibrissa scanning sensorimotor system. Neuron 72:455-468. CrossRef Medline

Leergaard TB, Bjaalie JG (2007) Topography of the complete corticopontine projection: from experiments to principal Maps. Front Neurosci 1:211-223. CrossRef Medline

Lisberger SG (2009) Internal models of eye movement in the floccular complex of the monkey cerebellum. Neuroscience 162:763-776. CrossRef Medline

Mao T, Kusefoglu D, Hooks BM, Huber D, Petreanu L, Svoboda K (2011) Long-range neuronal circuits underlying the interaction between sensory and motor cortex. Neuron 72:111-123. CrossRef Medline

Matyas F, Sreenivasan V, Marbach F, Wacongne C, Barsy B, Mateo C, Aronoff R, Petersen CC (2010) Motor control by sensory cortex. Science 330: 1240-1243. CrossRef Medline

Middleton SJ, Racca C, Cunningham MO, Traub RD, Monyer H, Knöpfel T, Schofield IS, Jenkins A, Whittington MA (2008) High-frequency network oscillations in cerebellar cortex. Neuron 58:763-774. CrossRef Medline

Na J, Kakei S, Shinoda Y (1997) Cerebellar input to corticothalamic neurons in layers V and VI in the motor cortex. Neurosci Res 28:77-91. CrossRef Medline

O'Connor SM, Berg RW, Kleinfeld D (2002) Coherent electrical activity between vibrissa sensory areas of cerebellum and neocortex is enhanced during free whisking. J Neurophysiol 87:2137-2148. Medline

Passamonti L, Novellino F, Cerasa A, Chiriaco C, Rocca F, Matina MS, Fera F, Quattrone A (2011) Altered cortical-cerebellar circuits during verbal working memory in essential tremor. Brain 134:2274-2286. CrossRef Medline

Popa D, Duvarci S, Popescu AT, Léna C, Paré D (2010) Coherent amygdalocortical theta promotes fear memory consolidation during paradoxical sleep. Proc Natl Acad Sci U S A 107:6516-6519. CrossRef Medline

Robinson FR, Fuchs AF (2001) The role of the cerebellum in voluntary eye movements. Annu Rev Neurosci 24:981-1004. CrossRef Medline

Ros H, Sachdev RN, Yu Y, Sestan N, McCormick DA (2009) Neocortical networks entrain neuronal circuits in cerebellar cortex. J Neurosci 29:10309-10320. CrossRef Medline

Rowland NC, Goldberg JA, Jaeger D (2010) Cortico-cerebellar coherence and causal connectivity during slow-wave activity. Neuroscience 166:698-711. CrossRef Medline

Sawyer SF, Young SJ, Groves PM, Tepper JM (1994) Cerebellar-responsive neurons in the thalamic ventroanterior-ventrolateral complex of rats: in vivo electrophysiology. Neuroscience 63:711-724. CrossRef Medline

Soteropoulos DS, Baker SN (2006) Cortico-cerebellar coherence during a precision grip task in the monkey. J Neurophysiol 95:1194-1206. Medline

Steriade M, Contreras D, Amzica F, Timofeev I (1996) Synchronization of fast $(30-40 \mathrm{~Hz})$ spontaneous oscillations in intrathalamic and thalamocortical networks. J Neurosci 16:2788-2808. Medline

Strick PL, Dum RP, Fiez JA (2009) Cerebellum and nonmotor function. Annu Rev Neurosci 32:413-434. CrossRef Medline

Sultan F, Augath M, Hamodeh S, Murayama Y, Oeltermann A, Rauch A, Thier P (2012) Unravelling cerebellar pathways with high temporal pre- 
cision targeting motor and extensive sensory and parietal networks. Nat Commun 3:924. CrossRef Medline

Teune TM, van der Burg J, van der Moer J, Voogd J, Ruigrok TJ (2000) Topography of cerebellar nuclear projections to the brain stem in the rat. Prog Brain Res 124:141-172. CrossRef Medline

Thompson RF (2005) In search of memory traces. Annu Rev Psychol 56:1-23. CrossRef Medline
Tseng YW, Diedrichsen J, Krakauer JW, Shadmehr R, Bastian AJ (2007) Sensory prediction errors drive cerebellum-dependent adaptation of reaching. J Neurophysiol 98:54-62. CrossRef Medline

Verret L, Mann EO, Hang GB, Barth AM, Cobos I, Ho K, Devidze N, Masliah E, Kreitzer AC, Mody I, Mucke L, Palop JJ (2012) Inhibitory interneuron deficit links altered network activity and cognitive dysfunction in Alzheimer model. Cell 149:708-721. CrossRef Medline 